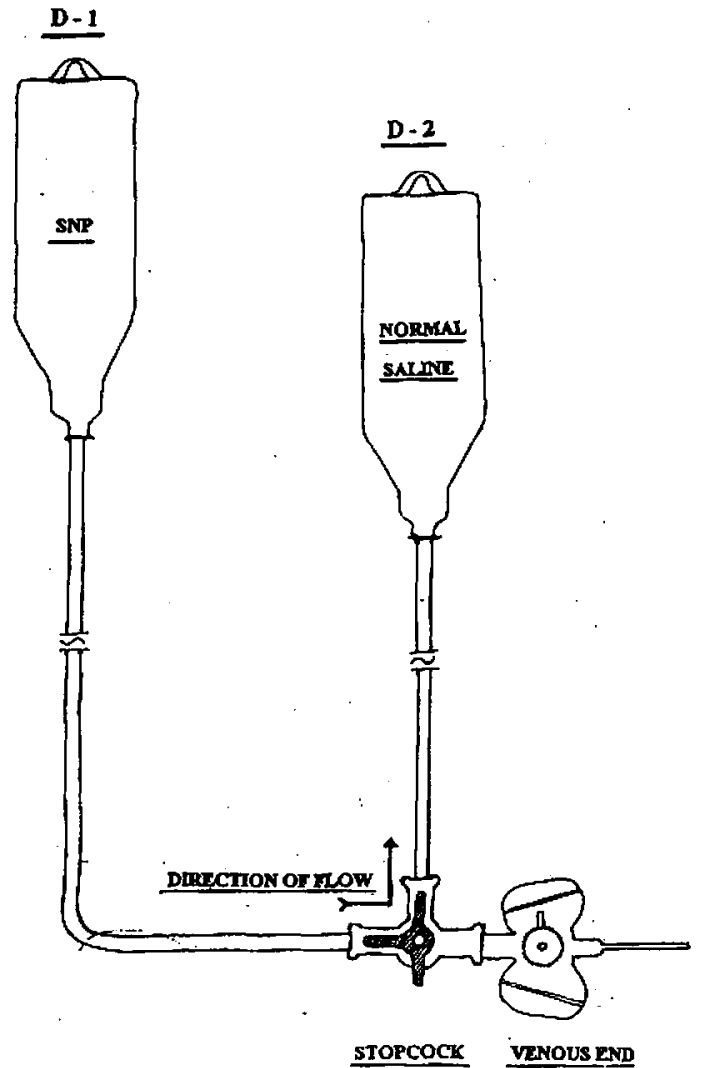

Fig. : Showing likely position of threeway stopcock leading to retrograde flow sia and surgery was absolutely uneventful.

Retrospectively, while auditing the event, the function of the three-way stopcock used was analyzed for any lcaks or flow in unintended direction. The stop-cock was found to be normal. However the possibility of SNP solution finding its way into D-2 while connecting it to the threeway could not be ruled out. Therefore it was thought that the venous end of the three-way was turned off accidentally thereby bringing D-1 and D-2 in continuity and allowing retrograde flow in D-2. To confirm this we carried out a simple experiment using the two drip sets and simulating the circumstances (Fig). It was evident that the moment $D-1$ was placed at a height of $10 \mathrm{~cm}$ above $D-2$, the solution began to flow in to D-2 and within 8-10 seconds the entire tubing and air chamber of D-2 was filled. We also measured this volume to be $12-15 \mathrm{~mL}$ approximately. Thus it appears rational to believe that there indeed was transfer of about 1200 to $1500 \mu \mathrm{g}$ of SNP in D-2 which could have occurred anytime during controlled hypotension. This also explains precipitous fall in MAP each time the infusion was started.

We conclude by emphasizing that a potent drug infusion like SNP should always be set up separately and should not be used for any other purpose in order to avoid treading on a path to disaster.

Lt Col PS GARCHA , Maj DK SREEVASTAVA ${ }^{+}$

${ }^{*}$ Reader, ${ }^{+}$Clinical Jutor, Dept of Anaesthesiology, Armed Forces Medical College

Pune - 411040

\title{
HIGH ALTITUDE PULMONARY OEDEMA
}

\section{Dcar Editor,}

I read with interest the arlicle "Nested case-control analysis of the risk factors for high altitude pulmonary oedema" by Lt Col Rajiv Bhalwar et al (MJAFI 1995; 51 : 189-93).

One of the conclusions made by the authors has been that they found no difference in the incidence of HAPO amongst fresh inductees and reinductees. They have gone further to add that in the previous studies, total number of cases were considered and not the proportion of events, which was the reason for the higher incidence of HAPO in reinductees.

There is a simpler conclusion which can be drawn from the results available so far, which will support the obscrvations of earlier and reputed workers in this field. Each induction and rcinduction are to be treated as fresh events for the purpose of statistical analysis, an induction being event No $l$ and the reinductions which follow being events 2,3 and so on. A soldier is thus exposed to five to six such events during his total stay at high altitude location. Subsequently it can be easily proved from most available data on the subject that the inciderice of HAPO is significantly higher in events 2 and 3 (reinduction events). The segregation of reinductions into separate events permits better and unbiased comparison between induction and reinductions.

\section{Maj RG PODUVAL}

Classified Specialist Medicine

153 General Hospital

C/O $56 \wedge \mathrm{PO}$ 